\title{
A comparative assessment of consumer and non-consumer preference for beef cuts consumption in Malaysia
}

\begin{abstract}
Malaysia is currently enjoying an economic revival, resulting in a rising per capita income and an increasing urban population. There are consumers whose taste buds have become more accustomed to international cuisines, including meaty Western food, to satisfy their quest for diversity in their new lifestyles. This group of consumers in Malaysia plays an important role in shaping the rising trend in the consumption of meat products, and this changing attitude calls for empirical research to clarify factors shaping it. The results also indicate that there are three factors (attributes of beef cuts, quality and safety, and the variety of Malaysian dishes) that greatly influence the preference for beef consumers toward their consumption of beef cuts. It was also determined that four factors that influenced the preference for non-beef consumers are price of beef cuts, lifestyle, risk associated with beef cuts consumption, taste, and preferences influencing non-beef consumers.
\end{abstract}

Keyword: Consumer preference; Beef cut; Consumer and non-consumer; Malaysia 